\title{
Pregoneros de la doctrina. Prácticas de identificación y sentidos de la acción entre los alumnos provincianos de la Escuela Superior Peronista (1952-1955)
}

\section{Heralds of the doctrine. Practices of identification and meanings of action among provincial students of the Escuela Superior Peronista (1952-1955)}

\author{
Mariana Garzón Rogé \\ Instituto de Historia Argentina y Americana Dr. Emilio Ravignani, \\ Universidad de Buenos Aires, \\ Consejo Nacional de Investigaciones Científicas y Técnicas (Argentina) \\ mariana.garzon.roge@gmail.com \\ mgarzonroge@conicet.gov.ar
}

\begin{abstract}
Resumen
El artículo sigue los rastros de alumnos del interior del país que viajaron a Buenos Aires para asistir a los cursos de capacitación de la Escuela Superior Peronista. Estos activistas presentaron sus postulaciones en 1952 y, después de egresar de los cursos que se realizaron en 1953, volvieron a sus lugares de origen en donde se propusieron, entre 1954 y 1955, organizar las regionales locales. A través del análisis de sus legajos personales, se ponen en evidencia modos en los que estos activistas a ras del suelo desplegaban sus prácticas de identificación, produciendo en situación su condición de peronistas, en diálogo con críticas y pruebas a las que se consideraban sometidos. El seguimiento de los actores permite describir, asimismo, procesos de gestación desde debajo de formas legítimas e ilegítimas de actuar al interior del movimiento que a menudo han sido observadas como resultado de un disciplinamiento político cenital.
\end{abstract}

Palabras Clave

Peronismo; Escuela Superior Peronista; Prácticas de Identificación; Historia Pragmática.

\begin{abstract}
The article follows the traces of students from the interior of the country who traveled to Buenos Aires to attend the training courses of the Escuela Superior Peronista. These activists submitted their applications in 1952 and, after graduating from the courses held in 1953, returned to their places of origin where they tried to organize, between 1954 and 1955, the local regional ones. Through the analysis of their personal files, the ways in which these activists at ground level deployed their identification practices become evident. They produced in situation their condition of Peronists, in dialogue with criticisms and proofs to which they considered themselves subjected. The tracking of the actors also permits to describe processes of genesis from below of legitimate and illegitimate ways of behaving
\end{abstract}




\section{Mariana Garzón Rogé}

within the movement that have often been observed as the result of a zenithal political discipline.

\section{Keywords}

Peronism; Peronist Superior School; Identification Practices; Pragmatic History.

La Escuela Superior Peronista (en adelante, ESP) fue creada en diciembre de 1950 para contribuir en la formación doctrinaria de los cuadros políticos del movimiento liderado por Juan D. Perón. Hasta entonces, los peronistas habían convivido en un paisaje de movilización sostenida y reverberante. Esa efervescencia se había dado de manera espontánea, al calor de múltiples conflictos facciosos entre los diversos núcleos que habían acompañado la candidatura presidencial después de las jornadas de octubre de 19451. Las transformaciones que se operaron en el peronismo alrededor de 1950, entre las cuales se encuentra la fundación de la ESP, fueron interpretadas en la historiografía como momentos del pasaje hacia un modelo organizativo más vertical y desmovilizado (O. Aelo, 2016; 0. H. Aelo \& Quiroga, 2006; Barry, 2009; Mackinnon, 2002; Quiroga, 2012; Macor \& Tcach, 2013). Esa narrativa se basó en investigaciones que renovaron por completo el panorama de los estudios sobre el peronismo en las últimas décadas. La puesta en disponibilidad de documentación relativa a la organización y funcionamiento de la ESP en el Archivo General de la Nación fue clave para que esa institución sumara su aporte a aquella historia ${ }^{2}$.

Un significativo trabajo, preliminar porque fue presentado en una reunión académica, asoció la creación de la ESP a una necesidad del peronismo por actualizar la mística inicial que el gobierno estaba perdiendo después de algunos años en el poder, en el contexto de problemas económicos insoslayables. Se trató, en la perspectiva de Patricia Berrotarán, de un intento por reducir los imaginarios múltiples que habitaban al heterogéneo peronismo y de proponer un nuevo orden: "la escuela era el intento tardío o una respuesta tardía al fracaso de conformar una estructura política desde 1946; era la búsqueda de la unificación y la homogeneización de lo que se entendía como peronismo" (Berrotarán, 2010, p. 6). El discurso peronista habría abandonado su versión confrontativa para convertirse en instrumento de cohesión, siguiendo los deseos de una "burocracia partidaria" preocupada por

\footnotetext{
${ }^{1}$ Muchas investigaciones han discutido la hipótesis de la pasividad de los peronistas que rigió los primeros análisis académicos sobre el tema. Actualmente podemos hablar del pasaje, no completo, de una hipótesis de pasividad a una hipótesis de mayor agencia de parte de los peronistas. Muchas parcelas de la historiografía han fortalecido esta tendencia común a "detectar vida" allí en donde se había creído que no había nada para investigar: el Partido Peronista, la sociedad civil, los peronismos provinciales, instituciones como la Confederación General de los Trabajadores, etc. La metáfora proviene de una conocida cita de Félix Luna quien, a mediados de los años ochenta, aseguró que no valía la pena prestarle atención al Partido Peronista porque era una "cáscara vacía", un "cadáver lujosamente velado" (Luna, 1984).

2 La revista de la ESP, Mundo Peronista, captó la atención de los investigadores de manera más temprana (Morales, 2017; Panella, 2008; Panella \& Korn, 2010; Piñeiro Iñíguez \& Baschetti, 2015; Qués, 2008).
} 


\section{Pregoneros de la doctrina. Prácticas de identificación y sentidos de la acción entre los alumnos provincianos de la Escuela Superior Peronista (1952-1955)}

establecer ideas aceptables e inaceptables de ser un "verdadero peronista" (Berrotarán, 2010, pp. 6-8). La creación de la ESP fue uno de los instrumentos a través de los cuales se buscó el disciplinamiento del oficialismo, más allá de que esas aspiraciones -advertía la misma autora- no dieran los resultados esperados (Berrotarán, 2010, p. 10). Una investigación más reciente también aportó elementos para la comprensión de la ESP como institución clave en la difusión de la doctrina y la formación de sus cuadros políticos. La atención puesta en los planes de estudio que se impartían en los cursos, así como en las publicaciones y los perfiles de estudiantes y docentes, alentaron a Ariana Leuzzi a afirmar que la ESP fue "tan sólo el eslabón final de toda una cadena de instituciones creadas a nivel barrial y regional, para llevar adelante el proyecto de acercar una doctrina homogénea a las masas" (Leuzzi, 2016, p. 54) ${ }^{3}$.

Este artículo converge con sus antecedentes en el interés por la ESP como un territorio relevante para comprender la política de los primeros activistas peronistas. Relativiza, en el mismo movimiento, el lugar de esa entidad como dispositivo de adoctrinamiento y encuadramiento de la militancia, no porque no haya tenido esa función en la imaginación de sus creadores o en las ensoñaciones de sus participantes, sino porque considera que, a través de un ejercicio de suspensión del juicio, será posible observar cómo actuaban quienes habitaban ordinariamente la vida de esa institución. Ese ejercicio constituye una necesidad de la investigación que requiere una explicación. Concebir a la ESP como dispositivo de homogenización de la militancia implica haber optado por un dilema sobre la acción de los peronistas: ser correas de trasmisión ideológica en el disciplinamiento del movimiento o, por el contrario, contestar los intentos de disciplinamiento en gesto de indisciplina. Estos polos, habituales en los estudios sobre el peronismo, dan vida a un marco explicativo común que opone pulsiones distintas para darle al peronismo su tono político específico. Por un lado, un poder superior avanzando implacablemente desde arriba hacia abajo y, por otro, agencias movidas por una fuerza contrahegemónica, operando desde abajo hacia arriba. Podríamos, desde ese punto de vista, buscar entre los alumnos de la ESP actitudes rebeldes, gestos disconformes, subterfugios de contestación, que permitieran imaginar que ni siquiera en el examen de la institución más catequista de la década la homogeneidad y la disciplina fueron la regla. El peronismo sería todavía ese fenómeno "ambivalente" o "contradictorio" (Macor \& Tcach, 2013; Karush, 2016), aunque situando su punto de equilibrio más cerca de la agencia que de estructura. Las proporciones de esa alquimia entre el poder de la agencia desde abajo y el peso de las estructuras de poder superior dependen del punto de vista del analista. Con los mismos datos, se puede interpretar que el peronismo funcionaba de manera

\footnotetext{
${ }^{3}$ Se advierte en este trabajo el legado del trabajo de Mariano Plotkin. El peronismo pretendió "peronizar" a la sociedad imponiendo una "unidad espiritual" en la cultura política (Plotkin, 1993, 2007). En un sentido similar, una ponencia de Marcelo Camusso y María Eugenia Santiago reflexionó sobre la ESP como sede de una traslación de estrategias y saberes de parte de Perón del campo militar al campo político (Camusso \& Santiago, 2008).
} 


\section{Mariana Garzón Rogé}

centrípeta, restando autonomía a sus adherentes, reivindicándolos quizás, pero siempre nutriendo el estilo paternalista de su configuración; y también se puede diagnosticar la persistencia de dinámicas plebeyas irredentas que desbordaron históricamente los deseos de la estructura carismática, gestando así su dimensión más potente y duradera.

Más que indagar en el sentido de la acción de los peronistas en el seno de la ESP (ser evangelizadores o rebeldes soterrados) la preocupación de este artículo reside en describir modos en los cuales impulsaban concretamente su acción en el interior de esa institución. Un amplio interés por describir el cómo de sus comportamientos, por supuesto, no tiene una sola ni breve respuesta, sino una inspiración general por tomar en serio a los actores, en el sentido que le daba Bernard Lepetit a esa reivindicación, es decir, observando la acción sin ningún sentido a priori (Lepetit, 1995b). El texto sigue los rastros de alumnos del interior del país que viajaron a Buenos Aires en el otoño de 1953 para asistir a los cursos de capacitación dedicados a formar los cuadros políticos de las provincias y territorios. Estos peronistas presentaron sus postulaciones en 1952 y, después de egresar de los cursos, volvieron a sus lugares de origen en donde se propusieron, entre 1954 y 1955, organizar las regionales 4 . Para ello, se utilizaron sus legajos personales alojados en el Fondo Documental de la Fiscalía Nacional para la Recuperación Patrimonial perteneciente al Archivo General de la Nación Argentina ${ }^{5}$. Ese acervo contiene material secuestrado por las llamadas "Comisiones Investigadoras" que, luego del golpe de Estado que clausuró la primera década peronista en 1955, recabaron y sistematizaron elementos destinados condenar el supuesto carácter delictivo e irregular del gobierno depuesto (Ferreyra, 2016b, 2016a, 2018). Como ha sido señalado para otros archivos de las mismas características, los de la "Revolución Libertadora" contienen material de primera mano sobre el período peronista (Da Silva Catela, 2002, p. 397).

Las postulaciones de quienes se candidatearon para tomar los cursos constituyen el foco del primer apartado. Ellas permiten registrar modos en los cuales era producida públicamente una condición de peronista, en diálogo con críticas y pruebas a las que los aspirantes se consideraban sometidos. En un segundo momento, se examinan distintas demandas que realizaron los peronistas egresados al regresar sus lugares. El análisis de pedidos de mejoras laborales permite advertir una operación común: la de solicitar algo en nombre de una "obligación peronista" evadiendo la pretensión ilegítima de creerse "con derechos" a tener algún tipo de trato preferencial en tanto miembro de la ESP. Por último, el artículo se detiene en el caso de un alumno de Santiago del Estero que es cuestionado al volver a su

\footnotetext{
${ }^{4}$ Leuzzi investigó el proyecto de creación de escuelas en el interior del país y recuperó detalles organizativos del curso que abordamos. Mercedes Prol también rescató la preocupación de la ESP por crear escuelas en las provincias (Prol, 2012).

${ }^{5}$ Se trata de la Comisión $\mathrm{N}^{\circ} 52$ dedicada a colectar y evaluar la documentación de la ESP. En adelante "AGN - FNRP - C.52 - $\mathrm{N}^{\circ}$ de expediente". Se trata de 7 cajas que contienen documentación variada (legajos personales de alumnos y personal, nóminas de docentes y personal, presupuestos, versiones taquigráficas de clases, entre otras cosas).
} 


\section{Pregoneros de la doctrina. Prácticas de identificación y sentidos de la acción entre los alumnos provincianos de la Escuela Superior Peronista (1952-1955)}

provincia "por creerse con derechos" para actuar en la política local en tanto que egresado de la ESP. La denuncia permite comprender cómo se producían pruebas legítimas para cuestionar el comportamiento de un activista, en el marco de una creciente dinámica de denuncias intrapartidarias y de medidas disciplinarias internas, al mismo tiempo que se validaban "desde abajo" modos de construcción política vertical. A modo de cierre, a la luz de la historia pragmática (Cerutti, 2011; Garzón Rogé, 2017a), proponemos una reflexión sobre el tratamiento de las fuentes documentales en el análisis de la acción de los activistas peronistas. Esa reflexión constituye una invitación a describir la política de los peronistas ya no como dominio delimitado por la lente del observador sino como actividad impulsada y significada como tal en el plano de las situaciones vividas (Berger \& Gayet-Viaud, 2011).

\section{Pruebas de peronicidad: el incesante trabajo de crear la identidad peronista}

"Los grupos no son cosas silenciosas, sino más bien el producto provisorio de un clamor constante hecho de millones de voces contradictorias que hablan acerca de lo que es un grupo y de quién corresponde a cuál" (Latour, 2008, p. 53).

El curso de la ESP para alumnos de las provincias y territorios comenzaría en Capital Federal a fines de mayo de 1953. Los interventores del partido, siguiendo una lógica distributiva entre las tres ramas, debían haber elevado, para entonces, una nómina de candidatos representando al Partido Peronista, al Partido Peronista Femenino y a la Confederación General del Trabajo de cada jurisdicción. Los seleccionados residirían en la ciudad de Buenos Aires durante el plazo de tres meses. Debían llenar un formulario y pasar una "prueba de admisión" para ser aceptados. El formulario solicitaba información personal, datos familiares, actividad profesional, antecedentes policiales y detalles sobre su grado de instrucción. Además, pedía detalles sobre la "actuación política" del candidato: fecha de afiliación al Partido Peronista, unidad básica de afiliación, si había estado asociado a alguno de los partidos del Movimiento Peronista antes de las elecciones de 1946, cuál había sido su actuación política hasta el inicio del gobierno militar de 1943 (en qué partido político y cuál había sido la eventual causa de separación), cuál había sido su desempeño público durante los años del gobierno militar y a partir de las elecciones de 1946 que habían dado por ganador a Perón, qué actividades doctrinarias había realizado (conferencias y publicaciones) en ese período, qué cargos políticos había ocupado en el Partido Peronista, qué otras tareas había cumplido sin cargo partidario, misiones, trabajos especiales, cargos públicos. ¿Había recibido sanciones disciplinarias del partido? El formulario, finalmente, pedía datos sobre participación gremial o sindical de los postulantes: sindicato y fecha de afiliación, actuación 


\section{Mariana Garzón Rogé}

sindical previa, durante el gobierno militar y luego de la victoria del peronismo en 1946, tareas de organización y cargos ejercidos ${ }^{6}$.

La lectura de las decenas de legajos personales revela que los aspirantes reivindicaban asiduamente ser peronistas de la primera hora. No se presentaban como recién llegados al movimiento, se esforzaban por construir una narrativa en la que se habían dejado conquistar por el fenómeno político en marcha en el mismo momento en el que habían tomado conocimiento de su existencia, o muy poco después. Muchos afirmaban no haber tenido participación política antes de junio de 1943, salvo quienes habían tenido una actuación notable en los ámbitos locales. Si habían estado afiliados a algún partido, la causa de separación evocada era la simpatía que habían sentido con la llegada de Perón al poder. La mayoría se identificaba como "colaborador" del Partido Laborista o de la Unión Cívica Radical Junta Renovadora durante la campaña electoral de 1946. Después, según afirmaban, habían sido "propagandistas" en momentos electorales y organizativos. Entre las actividades doctrinarias realizadas mencionaban haber participado de conferencias en unidades básicas, de actos escolares y reuniones públicas. Entre las publicaciones de su autoría aludían a poesías dedicadas a Perón y Evita, a volantes sobre la situación política y declaraciones gremiales. Entre las tareas políticas cumplidas mencionaban campañas callejeras contra el agio, acciones para difundir el plan económico del gobierno, actividades proselitistas, haber sido delegados en congresos y reuniones partidarias o de diversas agrupaciones peronistas.

José Alberto Suárez, por ejemplo, había nacido en Santiago del Estero en 1920 y era director de la Escuela Nacional $N^{\circ} 362$ en esa provincia desde 1946. Si conseguía convertirse en alumno de la ESP, afirmaba, conocería la capital del país. Estaba afiliado a la unidad básica de Suncho Corral desde 1947, momento hasta el cual decía haber estado afiliado al Partido Laborista. No consignaba otras actividades políticas antes de junio de 1943. Había organizado, según informaba, la unidad básica de Pozo del Toba, de la que había resultado elegido secretario general por dos períodos, con mandato hasta 1958. Como tareas políticas desempeñadas, indicaba haber hecho uso de la palabra en un acto escolar por el Día de la Lealtad y en ocasión de un desagravio a la memoria de la difunta Eva Perón. Había sido, además, fiscal general en las elecciones presidenciales de noviembre de 1951. Estaba afiliado al sindicato de la Agremiación del Docente Argentino7.

Estos formularios se acompañaban de una declaración en donde el candidato juraba su lealtad hacia Perón y la memoria de Eva Perón y rubricaba un "ideario de la acción doctrinaria del Movimiento Peronista". Luego, había un espacio en el que debían consignarse nombre, apellido y dirección de "personas de responsabilidad sindical, política o gubernamental que puedan dar referencias" de los postulantes ${ }^{8}$. Algunas veces, esas referencias estaban firmadas por figuras de cierto reconocimiento de los

\footnotetext{
${ }^{6}$ AGN - FNRP - C.52 - múltiples expedientes.

${ }^{7}$ AGN - FNRP - C.52 - Exp. 107.268.

${ }^{8}$ AGN - FNRP - C.52 - multiples expedientes.
} 


\section{Pregoneros de la doctrina. Prácticas de identificación y sentidos de la acción entre los alumnos provincianos de la Escuela Superior Peronista (1952-1955)}

peronismos vernáculos: gobernadores, ministros, interventores, legisladores, dirigentes partidarios o sindicales.

Los aspirantes enviaban el formulario a la ESP por correo, acompañado de las "pruebas de admisión" escritas de puño y letra o a máquina. Estas pruebas consistían en dos textos, uno de ellos relativo a una de "Las 20 verdades peronistas" y otro a un pensamiento de Perón o Eva Perón que les era asignado en el momento de retirar el formulario de la sede partidaria. Al catamarqueño Julio César Santillán, por ejemplo, le había tocado escribir sobre la idea de que "Para un peronista no puede haber nada mejor que otro peronista". El texto que envió a la ESP comenzaba de este modo:

Antes de abordar este tema estimados compañeros, vivamos los nombres de nuestros líderes Perón y Eva Perón. -VIVA PERÓN!; VIVA EVA PERÓN!; También los invito a guardar un minuto de silencio en memoria de la Jefa Espiritual de la Nación, María Eva Duarte de Perón. Ahora bien, son mis deseos ardientes que estas mis palabras sean de provecho y que cuando Uds. regresen a sus hogares lleven consigo algo en sus mentes que les sean de utilidad?.

¿Plagiaba un discurso oral de los que habitualmente aparecían en los diarios de la época? ¿Se inspiraba en instrucciones sobre cómo hablar en público y no encontró razones para adaptarlas al discurso escrito? ¿Qué hacer con estos textos de primera mano en los que los peronistas teorizaban sobre lo que era o debía ser el peronismo, en los que los involucrados hablaban pomposamente para decir lo que suponían que los funcionarios de alto rango querían escuchar? Si aceptáramos que no es posible saber con certeza qué motivaciones profundas había detrás de aquellos textos, que no tenemos acceso a las mentalidades peronistas, no renunciaríamos al análisis histórico, solo asumiríamos sus más flacas evidencias empíricas. La historia pragmática, en ese sentido, invita a indagar en la superficie de esas "pruebas de admisión", como de cualquier fuente histórica que se encuentra siempre reivindicando alguna cosa en el presente que les dio origen (Lepetit, 1995a; Cerutti, 2011; Torre, 2011; Chateauraynaud \& Cohen, 2016; Garzón Rogé, 2017a). En este caso, lo que se hace obvio es que los aspirantes buscaban producir para sí mismos una legitimidad en tanto que peronistas que resultara válida para otros peronistas que iban a evaluar sus candidaturas. ¿Cómo lo hacían? ¿Cómo se demostraban entre peronistas esa condición de peroncidad (Garzón Rogé, 2017b)? ¿En qué medida esas prácticas, que podríamos pensar como prácticas de identificación, constituyeron formas de hacer política al interior del movimiento?

El 7 de octubre de 1952 Manuel Raúl Palacio acompañaba su formulario con una nota aclaratoria relativa a la fecha de su afiliación al Partido Peronista. Explicaba que, si bien en ese documento se señalaba que había sido el 28 de abril de 1951, en realidad su "actuación y afiliación es muy anterior, como que es de antes del 24 de febrero de 1946 y en las filas del entonces Partido Laborista, en la sede de las calles Salta y Andrés Baranda de Quilmes". La “documentación respectiva”, justificaba, se le

${ }^{9}$ AGN - FNRP - C.52 - Exp. 107.262. 


\section{Mariana Garzón Rogé}

había extraviado y había "tenido que inscribirse nuevamente". Como prueba de una continuidad en su adhesión, Palacio enviaba "una citación a una reunión de afiliados del Partido que conservaba por casualidad" y que, a sus ojos, "confirma por su fecha, 30 de enero de 1948, que mi afiliación es anterior al año 1951". Después de esas precisiones, aclaraba que "no podía ser de otra manera por cuanto soy uno de los millares de argentinos que tuvo el honor de estar en la Plaza de Mayo la noche gloriosa del 17 de octubre de 1945, por lo cual me considero un auténtico descamisado y no de los que esperó el éxito para enrolarse en las filas del peronismo"10. ¿Auténtico descamisado u oportunista recién llegado? La distinción parece menos una exigencia del régimen que un modo en el cual los propios peronistas engendraron clivajes entre ellos, inventando artesanalmente tipos de trayectorias, condenando a quienes habían "esperado el éxito para sumarse". Se desplegaban pruebas de peronicidad, elementos capaces de dar cuenta públicamente de (o incluso construir) la legitimidad y la calidad de la adhesión política que se tenía con el peronismo, elementos que debían ser razonables, pertinentes y oportunos en su puesta en discurso.

Los formularios de los aspirantes y las pruebas de admisión a la ESP pueden ser leídos entonces como oportunidades aprovechadas por los activistas para ofrecer explicaciones y justificaciones relativas a diversos aspectos que podían ser materia de objeciones entre sus compañeros, potencialmente problemáticos o poco convenientes, instancias de elaboración de sus narrativas militantes, de sus prestigios, de sus trayectorias. A pesar de la deferencia y el evangelismo contenidos en formularios y "pruebas de admisión", la importancia atribuida desde abajo a la distinción entre verdaderos y falsos peronistas, entre peronistas de la primera hora y peronistas de último momento, emerge como parte de una conveniencia. Esa distinción existía en la retórica oficial, por supuesto, pero era producida también entre los peronistas que, como Manuel Raúl Palacio, buscaban conseguir una validación a través de su reivindicación, en el marco de una duda real o imaginaria de otros que decían valorar igualmente semejantes pruebas.

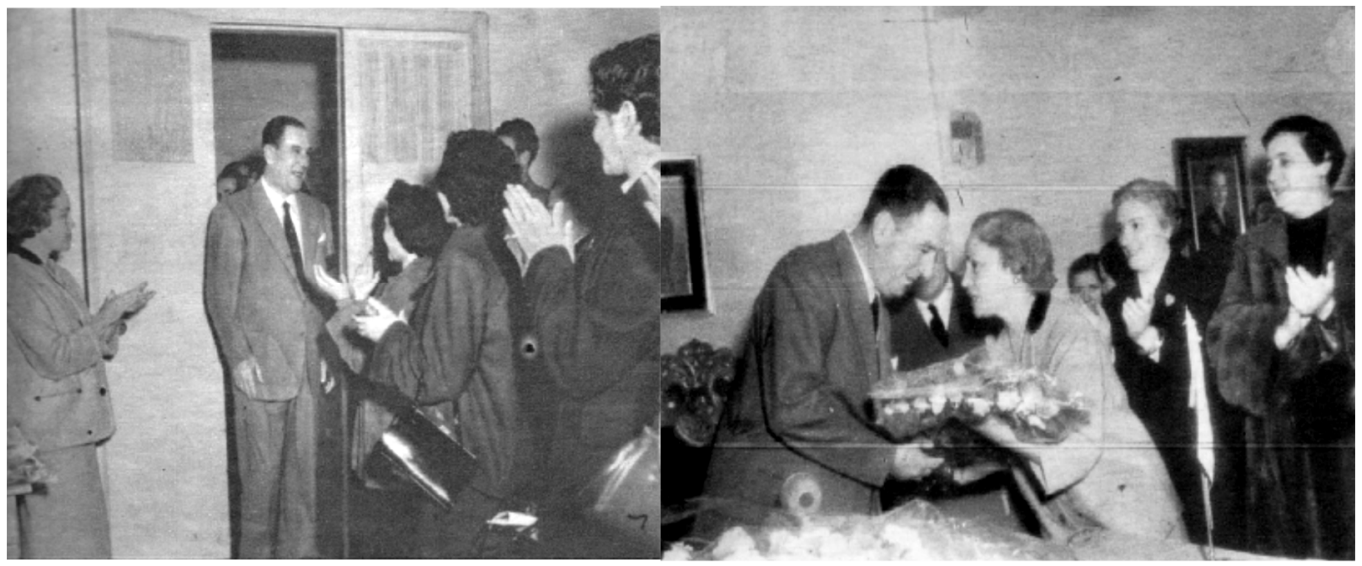

Perón llega para dar una clase magistral en el curso de provincias y territorios de la ESP (Mundo Peronista $\mathrm{N}^{\circ} 44$, junio de 1953)

${ }^{10}$ AGN - FNRP - C.52 - Exp. 107.272. 
Pregoneros de la doctrina. Prácticas de identificación y sentidos de la acción entre los alumnos provincianos de la Escuela Superior Peronista (1952-1955)

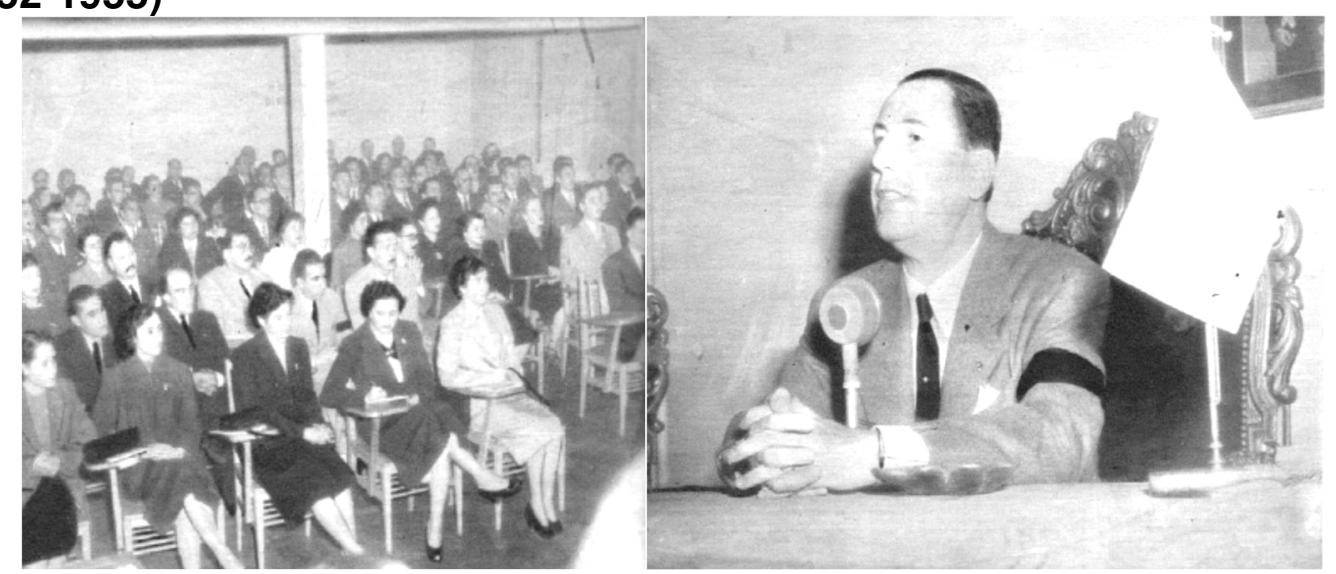

Curso de provincias y territorios de la ESP (Mundo Peronista $\mathbf{N}^{\circ} 44$, junio de 1953)

\section{Delimitar la acción legítima entre peronistas: derechos, privilegios y obligaciones}

"Trabajar en la Escuela Superior Peronista no da derechos. Es una simple obligación peronista" (Formularios de ingreso a la ESP, AGN - FNRP - C.52).

La leyenda del epígrafe estaba inscripta en la solapa de los formularios de ingreso a la ESP. El "ideario de la acción doctrinaria del Movimiento Peronista" señalaba que no debían atribuirse "derechos en el Movimiento, sino deberes y obligaciones, y están en permanente actitud de abnegación y de servicio". Era necesario, continuaba, comprender que "la jerarquía derivada de los cargos que ocupan [como miembros de la ESP], no se traduce en ningún privilegio"11. Estas frases no constataban un estado de cosas. Podríamos decir que eran, en sintonía con el razonamiento de Patricia Berrotarán, un intento por constituir determinadas prácticas como inaceptables (Berrotarán, 2010). Es posible, sin embargo, observar que estos mandatos no solo eran elaborados y sostenidos públicamente por las cúpulas del peronismo, tal como sucedía con las consignas de los "verdaderos peronistas", sino también alimentados y producidos por muchos de los que, a todo nivel organizativo y con fines prácticos diversos, veían en ellos la oportunidad de prestigiarse o de desprestigiar a otros, de producir prácticas de identificación convenientes.

Una vez terminados los cursos de la ESP en Buenos Aires, los egresados tenían por delante la misión de organizar de las regionales. Algunos aprovecharon para modificar algo de sus condiciones de trabajo: desde pedidos de ascensos o traslados hasta solicitudes para neutralizar a algún colega que interfería en su militancia. Estas demandas fueron cuidadosamente elaboradas para que no fueran leídas como una asunción de "privilegios" y sí, en cambio, como parte de los "deberes" que todo activista debía asumir si quería cumplir con el sagrado destino que le había sido encomendado. Implicaron, dicho de otro modo, un esfuerzo para definir situaciones (Thomas, 2005; Quéré, 1994). Los peronistas decían buscar cumplir con su mandato

${ }^{11}$ AGN - FNRP - C.52 - multiples expedientes. 


\title{
Mariana Garzón Rogé
}

de crear las escuelas, para lo cual debían constituir sus intereses de un determinado modo, como un interés de buen peronista.

Raúl Mendé, el director de la ESP, fue un aliado en esas gestiones de los viajeros. Su voluntad de extender los alcances de la escuela en el interior se traducía en incesantes movimientos para darles sustento. Transmitía, para ello, las solicitudes a su par, el ministro de Educación Armando Méndez de San Martín, señalando que un pedido de trabajo estaba de acuerdo con las "directivas expresas recibidas de la de la Autoridad Suprema de la Escuela Superior Peronista, el General Perón" según las cuales, evocando a Perón, "“nosotros aspiramos a que estas Escuelas estén organizadas cuanto antes. Hemos de ayudarles en toda forma desde la Escuela Peronista, desde el Gobierno Nacional y desde los Gobiernos Provinciales, para que ustedes puedan cumplir de la mejor manera su misión (Perón-25-8-53)'”'12. A menudo, el director aclaraba que los interesados no dejarían en ningún momento de cumplir con sus labores.

José Alberto Suárez, el maestro santiagueño, egresado de los cursos de capacitación de la ESP, era director de una escuela situada a 42 kilómetros de su lugar de residencia. Todos los días se trasladaba, según relataba en una carta fechada el 8 de agosto de 1953, desde Nueva Industria hasta la localidad de Beltrán, desde donde continuaba en sulky hasta la escuela. Esto significaba para él

\begin{abstract}
almorzar a las diez de la mañana y volver a mi casa a las veinte, luego de cumplir con mis tareas escolares. Como no escapará al elevado criterio de S.E. el Señor Ministro, esta situación me coloca en desventaja para cumplir mis funciones en la Escuela Provincial Peronista, por ello recurro a los buenos oficios de S.E. a efectos de solicitar mi traslado a la ciudad Capital, a la Escuela $\mathrm{N}^{\circ} 54^{\circ}$ "Argentina de Libarona" (cargo vacante actualmente) o a cualquiera de la misma Capital o ciudad de la Banda, distante 30' de ómnibus ${ }^{13}$.
\end{abstract}

En noviembre de 1953, su situación laboral no había mejorado, de modo que volvió a escribirle a Mendé, solicitando su traslado o ascenso a inspector de zona. El 19 de enero de 1954, el director insistió al ministro de Educación para que considerara el caso del santiagueño. El 27 de ese mes, Suárez volvía a escribirle pidiéndole que gestionara "con la mayor rapidez su traslado a la dirección de la Escuela Nacional $N^{\circ}$ 43 [...] en virtud de que estas vacantes son rápidamente llenadas". El egresado de la ESP buscaba las vacantes y las señalaba al director, quien a su vez activaba los pedidos ante el Ministerio de Educación. En marzo, una nota de este ministerio le informaba a Mendé que no era posible complacerlo en su pedido relativo a Suárez, dado que no existían cargos directivos disponibles en esa provincia14. Pocas semanas más tarde, el 15 de abril de 1954, surgía una nueva posibilidad señalada por el interesado, otra vez en la Escuela $\mathrm{N}^{\circ} 43$ de la ciudad de Santiago del Estero "por haberse producido recientemente una vacante por jubilación del titular de la

\footnotetext{
${ }^{12}$ AGN - FNRP - C.52. Exp. 107.268.

${ }^{13}$ AGN - FNRP - C.52. Exp. 107.268.

${ }^{14}$ AGN - FNRP - C.52. Exp. 107.268.
} 


\title{
Pregoneros de la doctrina. Prácticas de identificación y sentidos de la acción entre los alumnos provincianos de la Escuela Superior Peronista (1952-1955)
}

mencionada Escuela". Cuatro días después, el maestro santiagueño le agradecía a Mendé sus intentos por interceder, aunque hasta el momento no hubieran surtido efecto alguno.

\begin{abstract}
En su debida oportunidad he comunicado la existencia de vacantes, las que fueron llenadas, sin conseguir yo por ese medio una solución. Ahora me permito llevar a su conocimiento la existencia de tres (3) vacantes de Inspector de Zona, cargo inmediato superior al que desempeño desde hace nueve años en esta provincia. Dichas vacantes existen en la Inspección Seccional de la ciudad de Santiago del Estero donde debo cumplir mis tareas como egresado de la Escuela que se honra con su Dirección ${ }^{15}$.
\end{abstract}

A fines de mayo, el director reiteraba el pedido en favor de Suárez ante el Ministerio de Educación, asegurando que sería un modo de hacer realidad las directivas de Perón de "que las escuelas [regionales de la ESP] estén organizadas cuanto antes". Recién en agosto de 1954 informaron desde Educación a Mendé que se habían impartido instrucciones a la Dirección de la Enseñanza Primaria a fin de que Suárez desempeñara funciones en la Inspección Seccional de Santiago del Estero ${ }^{16}$.

Todavía en Buenos Aires, por su parte, Julio César Santillán ya había iniciado su pedido de traslado laboral desde la localidad de Saujil a la capital de Catamarca, al tomar conocimiento, también por su cuenta, de que se había producido una vacante en la Escuela Nacional $N^{\circ} 96$ de esa ciudad. Combinando planos argumentativos distintos (relativos a la vida partidaria, su conveniencia personal y los lazos de familia afectados por sus movimientos), Santillán explicaba al director de la ESP que:

Con mi traslado solucionaría el problema que crea la distancia para poder entregarme de lleno a la futura organización de la Escuela Peronista Provincial, rogando a Dios me dé fuerzas suficientes para que con mi modesta colaboración contribuya de una manera eficaz a la consolidación de este gran paso dentro de nuestro movimiento: el Adoctrinamiento del Pueblo.

Debo mencionar que mi iniciación tuvo lugar en el Territorio de los Andes (Antofagasta de la Sierra) y que toda mi carrera hasta el presente la realicé separado de mi familia, por la imposibilidad de llevarla ${ }^{17}$.

Meses más tarde, ya desde la capital catamarqueña y pronto a partir hacia Saujil para dar inicio al ciclo lectivo, Santillán insistió sobre su traslado a la capital de la provincia, ofreciendo también esta vez una panoplia de razones de distinta índole. Afirmaba que tendría que descuidar las tareas de la ESP, no porque ése fuera su deseo, sino porque no tenía otra opción, ya que su trabajo era su único medio de vida y de él dependía la manutención de su esposa y sus pequeños hijos. El pedido de traslado laboral aparecía en esa descripción de cosas como algo que fusionaba sus intereses personales con los intereses partidarios, a la vez que planteaba una crítica

\footnotetext{
15 AGN - FNRP - C.52. Exp. 107.268.

${ }^{16}$ AGN - FNRP - C.52. Exp. 107.268.

${ }^{17}$ AGN - FNRP - C.52. Exp. 107.262.
} 
sutil al sistema de formación de la ESP: ¿cómo era posible que el peronismo formara militantes y luego no propiciara las condiciones para que pudieran llevar a cabo su misión?:

\begin{abstract}
Señor Director, debo dejar expresa constancia de que si resuelvo alejarme de esta Capital a partir del $1^{\circ}$ de abril -de no resolverse favorablemente mi solicitud-, es porque es el único medio de vida mi profesión docente, con la cual mantengo a mi familia integrada por mi señora y tres hijitos de corta edad. Confieso con sincera y fervorosa fe peronista -tal como nos inculcó esa Escuela Superior Peronista de su digna Dirección- de que sentiría en el alma, por las razones de fuerza mayor enunciadas tener que alejarme sin colaborar como son mis deseos con la Escuela Peronista Provincial; después de haber puesto toda mi buena voluntad, disciplina y corazón de peronista, para aprender y sacar el máximo de aprovechamiento de las sabias enseñanzas del General Perón y de nuestra inolvidable Compañera Evita ${ }^{18}$.
\end{abstract}

Santillán realizaba una cuidadosa operación de despersonalización de su demanda, trayendo a colación aspectos de su vida personal que oficiaban como razón principal de que él no pudiera hacer aquel "sacrificio" amoroso por el peronismo del que tanto le habían hablado en la ESP. Esa despersonalización, al mismo tiempo, le permitía cuestionar las estructuras del poder peronista que no garantizaban una respuesta favorable a su pedido, pero lo hacía de una manera que preservaba lo que la pragmática lingüística llamaría los principios de la cooperación (Grice, 1991). Hilada en un lenguaje deferente, el egresado proponía una descripción de la situación en la cual su solicitud era en beneficio de la ESP y, en ninguna medida, una expresión de que él particularmente se sintiera con "derechos" a obtener algún rédito personal en su condición de egresado de la ESP. Ese cuidado permitía formular una crítica, pero protegiéndose.

El director de la escuela acompañó los pedidos de Santillán enviando cartas al ministro de Educación, del mismo modo que lo hizo en otros casos. Luego de lograr un traslado para trabajar en la Inspección Seccional de Catamarca, Santillán siguió intentando conseguir un puesto directivo. Él mismo avisaba a Mendé cuando se estaba por producir una vacante y el director enviaba carta al ministro de educación para gestionar esa posibilidad, con el dato en mano sobre la Escuela $\mathrm{N}^{\circ} 29$ o la $\mathrm{N}^{\circ}$ 43. Eran los peronistas los que activaban y movilizaban sus demandas en el marco de los "deberes" de buen peronista y, del mismo modo, el director de la ESP las redirigía e impulsaba hacia otros actores estatales para conseguir aquel objetivo común de inventar las escuelas en el interior del país:

Apelo a su reconocida benevolencia para solucionar los problemas que el suscrito le plantea en favor de los integrantes de los diversos Comandos Organizadores de las Escuelas Peronistas del interior, para que contemple la posibilidad de solucionar éste del compañero Santillán, con lo cual se le daría la

${ }^{18}$ AGN - FNRP - C.52. Exp. 107.262. 


\section{Pregoneros de la doctrina. Prácticas de identificación y sentidos de la acción entre los alumnos provincianos de la Escuela Superior Peronista (1952-1955)}

necesaria tranquilidad económica para su dedicación a las funciones que cumple en la Escuela Peronista de Catamarca ${ }^{19}$.

Lo que podría ser visto como un "derecho" o un "privilegio" y lo que podía ser visto como una "obligación" o un "sacrificio" entre los peronistas dependía, como se observa en los casos recuperados, de un trabajo semántico realizado para definir una situación, era un logro continuo de actores que conseguían validar artesanalmente diagnósticos legítimos en el marco de unas reglas compartidas que, a su vez, eran producidas en esos mismos cursos de acción. Los mismos peronistas movilizaban a través de las escalas, produciendo desde arriba y desde abajo, los pedidos y las soluciones a esos pedidos, los sentidos compartidos sobre lo que estaban haciendo.

Las pruebas que eran presentadas para justificar que una solicitud no implicaba atribuirse "privilegios" en el peronismo no siempre resultaban convenientes (Nachi, 2006; Thévenot, 1990, 2016). En esos casos, requerían de mayores ajustes. Salvador Sirena, de Formosa, decía que mientras estaba participando de los cursos de la ESP, había perdido la oportunidad de presentarse a una vacante de vicedirección, "resultando afectada mi carrera profesional". En noviembre de 1954 le pedía a Mendé que "allanara" las dificultades para que se lo promoviera a ese cargo. Atento a que su razonamiento podía no parecer convincente, aclaraba que su pedido no estaba "basado en ningún derecho como miembro de la Escuela Peronista de Formosa, sino como maestro que por circunstancias transitorias ha visto interrumpida su aspiración"20. El pedido no podía fundarse en un interés general del peronismo, pero incluso entonces se justificaba de una posible acusación en términos de abuso de su lugar de peronista. No tenemos información de que haya conseguido la promoción que solicitaba.

En mayo de 1954, Yolanda Castro, integrante del Comando Organizador de la Escuela Superior en Mendoza, denunciaba a uno de sus jefes por "amargarle la vida" al desprestigiarla frente a sus subordinadas en una biblioteca universitaria.

Señor [Jefe del Departamento de Escuelas Regionales de la ESP Raúl Horacio] Fonseca, a usted le expreso lo que al Señor Ministro [Raúl Mendé] me reservo de comunicarle para evitarle un mal momento al saber cómo es de desconsiderado el trato de uno de mis superiores para conmigo.

Desde que fui a cumplir con el curso de la Escuela Superior Peronista y ahora al saber que solicito el tiempo estrictamente necesario sin perjuicio de mis funciones, para trabajar en la organización de la escuela. Este señor es el bibliotecario de la Facultad de Ciencias Médicas "Doctor Tomás Perón", Anastasio Pimenides.

Lo más grave del caso es que a todas las empleadas de biblioteca les dice que a la Señorita Castro habrá que mandarle el sueldo a la casa, olvidándose este señor, que yo soy jefe de sección y ese personal trabaja

${ }^{19}$ AGN - FNRP - C.52. Exp. 107.262.

${ }^{20}$ AGN - FNRP - C.52. Exp. 107.267. 


\section{Mariana Garzón Rogé}

bajo mis órdenes, evidentemente lo hace a fin de que no se me tenga el respeto debido y les agrega, si ustedes quieren acomodarse tengan una Unidad Básica en su casa como la Señorita Castro.

Yo lo único que le pido a usted Señor Fonseca y de todo corazón, es, que interceda a fin de que este hombre no me siga molestando más, quitándome arbitrariamente mi concepto moral y amargándome la vida, por la única razón: que soy peronista completamente identificada con el Gobierno, haber concurrido a los cursos de la Escuela Superior Peronista y por último, tener una Unidad Básica Peronista Femenina en mi casa21.

Castro era Secretaría de la Unidad Básica Femenina de San José de Guaymallén, estaba afiliada al Sindicato del Personal de la Universidad Nacional de Cuyo en tanto auxiliar de la biblioteca de la Facultad de Ciencias Médicas. En otra carta, esta vez al ministro Mendé, solicitaba una constancia de sus actividades en la ESP para presentar ante la universidad, con el objetivo de que se le concedieran algunos días ("sin perjuicio de cumplir con mis obligaciones de empleada") para "organizar la escuela" y para "arbitrar todo lo necesario a fin de que el Excelentísimo Señor Presidente de la Nación logre inaugurar las escuelas simbólicamente el $1^{\circ}$ de junio del corriente año en todo el territorio de la Patria". La activista aprovechaba para manifestar su inquietud ante una situación que consideraba necesario modificar:

Como dato ilustrativo y a los fines que S.E. estime prudente, llevo a conocimiento de su ilustrado criterio que la recurrente trabaja con el horario común de todo el personal, incluso los días sábado por lo que prácticamente dispongo de poco tiempo en mis horas libres, para llevar a feliz término, la organización mencionada [de la ESP].

Yo esperaba como egresada de la Escuela Superior Peronista y dado la trascendental importancia de la organización y funcionamiento de la escuela a crearse y que debe de estar en las inquietudes de todo buen argentino, un espontáneo y gentil ofrecimiento del tiempo que se necesita para cumplir con esas tareas, como colaboración peronista, ya que el peronismo no se aprende ni se proclama: se comprende y se siente, ha dicho Perón ${ }^{22}$.

Las aclaraciones, los énfasis, los modos de la redacción de las misivas, dan cuenta de prácticas reflexivas destinadas a crear y sostener sentidos compartidos acerca de lo aceptable e inaceptable en el peronismo. Si Anastasio Pimenides podía ser denunciado como "amargándole la vida" a la señorita Castro, como desprestigiándola ante sus subordinados, si no le concedía un "espontáneo y gentil ofrecimiento del tiempo para cumplir con sus tareas" partidarias, no era porque ella se creyera con algún tipo de "privilegio" en tanto que peronista, sino porque él no comprendía que se trataba de obligaciones que debían "estar en las inquietudes de todo buen argentino".

El examen de estas peticiones de los egresados de la ESP nos pone en contacto con el dinamismo de la actividad política peronista durante la segunda presidencia. La

${ }^{21}$ AGN - FNRP - C.52. Exp. 23.037.

${ }^{22}$ AGN - FNRP - C.52. Exp. 23.037. 


\title{
Pregoneros de la doctrina. Prácticas de identificación y sentidos de la acción entre los alumnos provincianos de la Escuela Superior Peronista (1952-1955)
}

relación entre esos actores y las supuestas "burocracias partidarias" no parece haber sido estructurada unilateralmente, sino un cortejo de ida y vuelta artesanal en el que los participantes fueron tallando soluciones concretas a problemas cotidianos que se iban presentando en la vida política.

\section{Operaciones críticas entre peronistas: un caso denunciado}

"Los seres humanos [...] no se contentan con actuar o reaccionar a las acciones de otros. Vuelven sobre sus propias acciones u sobre las de otros para imponerles sus juicios, a menudo en términos del bien y del mal, es decir, juicios morales" (Boltanski, 2009, p. 18).

El trabajo de producción de pruebas de peronicidad suponía una indeterminación porque implicaba una reversibilidad que podía ser aguijada por las competencias críticas de otros actores (Boltanski, 2009; Barthe et al., 2013). En el expediente de José Alberto Suárez encontramos una denuncia anónima que lo acusaba de atribuirse "derechos" en tanto que egresado de la ESP. La acusación decía así:

\begin{abstract}
Como verá por el recorte adjunto, el señor ALBERTO SUÁREZ, egresado de la Escuela Superior Peronista, ha iniciado su récord [sic] político, actuando como Subdelegado de esa organización que en esta ciudad de Santiago del Estero ha sido desautorizada, según recorte también adjunto, por el Presidente del Consejo Superior del Partido.

Además el señor SUÁREZ aprovechando la entrada que se le brindaba en el Partido Peronista se ha ocupado de formular declaraciones falsas y certificar calumnias con infamias de su propia imaginación, contra dirigentes partidarios, a quienes suponía posibles candidatos a puestos electivos, a fin de abrirse paso para la realización de sus sueños de llegar al Senado de la Nación. Sirvió de instrumento para dañar a varios dirigentes llevando infamias a Control de Estado Provincial, lesionando algunas reputaciones momentáneamente. Si usted lo somete a un ligero examen verá que este hombre padece una tara mental, tal vez ocasionada por el exceso de alcohol que ingiere. Estos son los hombres que van a difundir la doctrina?23
\end{abstract}

Se adjuntaban dos recortes de prensa como respaldo. El primero era una información partidaria del "Movimiento de la Juventud Peronista", publicado el 7 de marzo de 1954. El segundo, una solicitada firmada por la "Juventud Peronista", publicada dos semanas después. Ambos materiales habían aparecido en el diario $E l$ Liberal. Con ellos se buscaba probar que Suárez contradecía las directivas partidarias. Para probarlo, fue necesario conectar quirúrgicamente los datos, operación que muestra la riqueza de las actividades críticas que eran puestas en juego a la hora de producir la facciosa y soterrada vida partidaria del peronismo. Vale la pena hacer foco en esa denuncia -que fue solo una de las miles que hubo en esos años, tal como testimonia la bibliografía sobre los procesos de disciplinamiento interno (Quiroga, 2017)- a fin de iluminar las consecuencias plurales de esa acción.

${ }^{23}$ AGN - FNRP - C.52. Exp. 107.268. 


\title{
Mariana Garzón Rogé
}

El primer recorte de prensa era una "información partidaria" que celebraba la formación de una "delegación regional del Movimiento de la Juventud Peronista" y que detallaba la composición de sus autoridades, entre quienes se encontraba el denunciado Suárez, como subdelegado regional. El segundo recorte de El Liberal era una solicitada que recuperaba la minuta de una reunión de militantes en el "Comando Provincial de Organización de la Juventud Peronista" local con el candidato a vicepresidente por el peronismo, Alberto Teisaire. Ese texto afirmaba que:

\begin{abstract}
Al ser interrogado por el Jefe del Comando de la Juventud, don Michel S. Correa, sobre si era verdad que otro movimiento titulado también de la juventud y que se estaba organizando en todo el país bajo las siglas "M.J.P." estaba autorizado por el Consejo Superior del Partido Peronista, el señor Contralmirante respondió que "era una vil mentira" y que en el Partido Peronista no se conciben "puntas de lanza" que tiendan a la formación de un RANCHO APARTE, que ya se habían tomado medidas disciplinarias en la Ciudad Eva Perón donde "10 gatos locos" habían pretendido confundir y sembrar la desorientación en la juventud invocando autorizaciones del Consejo Superior y exhibiendo documentos y fotografías falsas con los cuales trataban de demostrar prácticamente una situación de carácter oficial que no existía y que así como habían sido sancionados estos elementos en Eva Perón, lo serían también en la ciudad de Córdoba y en otras más de la República; terminó afirmando "que los que no estén de acuerdo con las directivas partidarias FORMEN UN PARTIDITO APARTE Y SE VAYAN". [...] Las palabras vertidas por el Señor Contralmirante [...] fueron extraídas de la versión taquigráfica ${ }^{24}$.
\end{abstract}

Las palabras de Teisaire podrían haber sido extraídas de la versión taquigráfica de la reunión, como la solicitada se encargaba de resaltar para reforzar su veracidad, aunque es incierto el hilvanado específico con el que el anónimo las engarzaba con la agrupación de Suárez. ¿Había censurado el alto dirigente la formación del grupo juvenil específico? No es posible afirmarlo. La anécdota de los "10 gatos locos" bien podría haber sido parte de otro momento de su conversación con los jóvenes, en relación a cualquier otro grupo o rumor sobre disidencias en el peronismo. Si la condena hubiera sido explícita, seguramente el "anónimo" habría aprovechado para citarla al pie de la letra. El armado argumental propuesto, en cambio, relacionaba elementos sueltos como pruebas de que el egresado de la ESP, quien tenía la misión de "difundir la doctrina", participaba de una agrupación juvenil que había sido desautorizada por el partido.

Lo que esta operación muestra es que la regla de no usar los cargos o los espacios que se asumían en el peronismo para entrar o hacerse valer en otros ámbitos de la política partidaria era una regla creada, sostenida y reafirmada por aquellos peronistas que podemos imaginar actuando "desde abajo" y que suelen ser pensados como víctimas de la "desmovilización" o de la "despolitización" supuestamente motorizada "desde arriba". ¿Y si esa desmovilización hubiera sido el resultado de miles de actividades producidas también "desde abajo"? ¿Y si esas acciones no fueran, en verdad, tanto una forma de la desmovilización como un modo

${ }^{24}$ AGN - FNRP - C.52. Exp. 107.268. 


\title{
Pregoneros de la doctrina. Prácticas de identificación y sentidos de la acción entre los alumnos provincianos de la Escuela Superior Peronista (1952-1955)
}

de hacer política al interior del peronismo que, solo como consecuencia, tuvo el efecto de configurar una estructura en la que aparentemente tenían menor incidencia? Más curioso todavía: ¿y si lo que llamamos desmovilización fue el resultado de mucha movilización? Lo que en el plano local santiagueño podía ser leído como un silvestre pleito vernáculo, al proyectarse en el juego de las escalas, se convertía en una denuncia sobre prácticas viciosas que debían ser erradicadas en nombre de la lucha contra los politiqueros, contra los malos peronistas. Su grandeza, en términos de la sociología de la crítica, era aumentada por los propios actores para desingularizar el pedido (Boltanski \& Thévenot, 1991; Boltanski, 2009).

La denuncia del "anónimo" respetaba y validaba dinámicas de domesticación de la militancia, intentando yuxtaponer la impugnación a Suárez con los mandatos vigentes sobre la obediencia y la verticalidad en el peronismo, en su propio beneficio. Podría haber sido formulada en un régimen de justificaciones diferente, personal, por ejemplo. Pero la denuncia de Suárez necesitaba aumentar su generalidad, transformarse mientras viajaba por las escalas para no ser leída como resultado de las luchas facciosas vernáculas y mostrarse, por el contrario, precisamente como una acción para terminar con el faccionalismo. Si el denunciante hubiera inscripto la denuncia en el plano personal o moral limitándose a denunciar que Suárez había lesionado algunas reputaciones de dirigentes locales o que era un borracho, no hubiera podido contar con las pruebas con las que contó para sostener sus acusaciones. Eran las pruebas posibles, en este caso la alquimia entre dos recortes de prensa y una lectura competente suturadora de vacíos, el marco en el cual una denuncia, se hacía legítima y escalable, podía salir de entre bambalinas y proponerse como un problema del peronismo todo. No sabemos si el anónimo consiguió desprestigiar a Suárez de alguna manera visible, pero sí podemos afirmar que su mismo intento era una jugada posible.

\section{La identidad peronista desde una mirada de historia pragmática: una reflexión final}

\begin{abstract}
"Menos me doy cuenta, a falta de tener o de buscar la información necesaria, de que están rivalizando por el poder, arreglando un conflicto pedestre o negociando una alianza matrimonial [...], más me golpea la extrañeza irreductible de sus mitos, de sus ritos o de sus creencias. Inversamente, más aprendo a describir lo que hacen, más se disuelve su insondable alteridad, esa grieta que parecía separarme para siempre de su manera de ver el mundo (de su "mentalidad")" (Bazin, 2008, p. 113).
\end{abstract}

La preocupación de los peronistas de gestar, sostener y defender su condición de peronicidad no era una costumbre (Bazin, 2008), ni parte de un peculiar estilo político (Knight, 1998). Se trataba de una condición útil en el presente de su acción: buscaban ser seleccionados, resolver un conflicto, legitimar pedidos, cuestionar a otros, crear y consolidar una organización más jerárquica, más carismática, dirimir asuntos organizativos, hacerse respetar, vengarse, crecer políticamente. La 


\section{Mariana Garzón Rogé}

detección de actividades de este tipo en una institución como la ESP arroja una imagen sugerente sobre las destrezas que desarrollaron los peronistas para habitar esa identidad común en permanente elaboración. Vistos de ese modo, y parafraseando el epígrafe del antropólogo Jean Bazin, nos golpea menos la extrañeza irreductible de gestos que podrían ser vistos como producidos por pasivos militantes embelesados por el carisma de su líder. Tampoco nos convence la hipótesis de que se trataba de plebeyos actores buscando radicalizar los límites del populismo nativo. La acción de los peronistas era, antetodo, plural: tenía diferentes sentidos convivientes, no contradictorios. Si, por un lado, aprovechaban efectivamente sus interacciones para peticionar, para fortalecerse, para crecer políticamente, en sintonía con la tesis que buscar detectar una mayor agencia en el activismo peronista, al mismo tiempo ponían en marcha modos específicos que iban alimentando un tipo de autoridad cada vez más centralizada como consecuencia y propiciando la expansión de prácticas de identificación personalistas y deferentes. ¿Estaban disciplinándose o resistiendo al disciplinamiento? Hacían las dos cosas al mismo tiempo, en una infinidad de situaciones, además de muchas otras.

Entonces, prácticas que a priori no tenían ningún sentido contundente para la investigación histórica podrían haber sido momentos en los que se dirimían asuntos importantes para los peronistas: la deferencia, la delación, la difamación, las expresiones emotivas, las anécdotas pequeñas, en definitiva, las formas "menores" de hacer política a menudo reducidas a una mentalidad populista (Zanatta, 2008). Los lenguajes identitarios edulcorados, rimbombantes, evangelistas, podrían no ser signo de una mentalidad melodramática herética que requiere de un buceo en las profundidades de la subjetividad sino herramientas de uso público con las que los nativos hacían distintas cosas que no conocemos suficientemente pero no por tratarse de una sustancia arcana sino por nuestra falta de información al respecto ${ }^{25}$. Los estudios más innovadores e inspiradores sobre la identidad peronista estuvieron ciertamente más cerca de una epistemología de la sospecha. Paradigmático es el análisis de Daniel James sobre la vida militante de una trabajadora de la carne y activista peronista de la localidad bonaerense de Berisso. En Doña María, su libro publicado en Argentina en 2004, es el investigador quien detenta el saber sobre un sentido que es desconocido para los actores de su narración, es él quien debe reponer capas ocultas de la cultura popular que subyacen en los comportamientos de las trabajadoras peronistas del interior bonaerense. A la manera del molinero de Carlo Gizburg, la María Roldán de James no sabe que es portadora de una cultura latente que hibrida aspectos de clase, género y religión popular. Su testimonio constituye un puente de acceso a ese mundo cultural y social fascinante en el que los hilos son movidos más allá de la acción.

En el paradigma de la sospecha, las fuentes suscitan una pregunta dirigida al historiador (¿qué hacer con ellas?). Para James se trató de una interrogación crucial

25 Para una revisión de los trabajos que abordan al primer peronismo desde la óptica melodramática ver El hecho maldito de Omar Acha y Nicolás Quiroga (Acha \& Quiroga, 2012). 


\section{Pregoneros de la doctrina. Prácticas de identificación y sentidos de la acción entre los alumnos provincianos de la Escuela Superior Peronista (1952-1955)}

cuando Roldán le recitó un poema que había escrito en ocasión de la muerte de su amiga Clarita, laboriosa víctima de la explotación industrial. El poema permaneció durante años para el historiador "en una suerte de limbo interpretativo, como una especie de joya anecdótica que yo debía desplegar en un gesto culminante, mientras me esforzaba por ejemplificar la creatividad y subjetividad de una trabajadora en $\mathrm{mi}$ análisis de su testimonio oral" (James, 2004, p. 239). Algo parecido emergió con el hallazgo de aquellos exámenes de admisión para tomar el curso de provincias y territorios de la ESP. ¡Peronistas a ras del suelo teorizando sobre el peronismo! James se propuso, sin embargo, ir "más allá de la inmediatez del impacto performativo del poema", "ir más allá de los significados al alcance inmediato de la comunidad a la cual se dirigía el poema, a fin de descubrir su subtexto" (James, 2004, p. 266). Elaboró entonces una lectura de ese testimonio más allá de la clase, que contemplara sentidos de género y religiosos, a la vez que morales comunitarios, tramados en un tinglado melodramático que constituyeron un signo de la amenaza potencial que implicaban los mismos peronistas para la armonía de la Argentina peronista. El poema para Clarita fue entonces una clave secreta para abrir significados ocultos, reprimidos, que habitaban en las profundidades de la subjetividad peronista (Varela, 2015). Este era el costado más herético, conflictivo, contradictorio y potente del peronismo.

Al valorizar desde la historia pragmática la pregunta por lo que las fuentes hacen ellas mismas, en su superficie y no como pantalla de otra cosa, la mirada que olfatea en los márgenes, en los indicios, en los signos textuales, deja lugar a la descripción de aspectos ciertamente más modestos de la experiencia pasada (Cerutti, 2011). En el recorrido de los legajos de los alumnos que viajaron para participar de la vida de la ESP observamos el permanente trabajo de los peronistas, tanto en el momento de sus candidaturas como luego al solicitar mejoras laborales, por modelar y cuidar una condición de peronistas. Esa condición, a menudo analizada en términos de identidad, al ser considerada como tal, abandona cualquier velo de exotismo y muestra su origen práctico en un sinfín de pequeñas instancias de la política situada.

\section{Bibliografía}

Acha, O., \& Quiroga, N. (2012). El hecho maldito. Conversaciones para otra historia del peronismo. Prohistoria.

Aelo, O. (2016). El Partido Peronista argentino: Diseños organizativos y prácticas políticas (1947-1955). Topoi, 17(33), 602-625. https://doi.org/10.1590/2237101x017033013 


\section{Mariana Garzón Rogé}

Aelo, O. H., \& Quiroga, N. (2006). Modelos en conflicto. El Partido Peronista en la provincia de Buenos Aires, 1947-1955. Estudios Sociales, Revista Universitaria Semestral, 30, 69-96.

Barry, C. (2009). Evita Capitana: El Partido Peronista Femenino, 1949-1955. EDUNTREF.

Barthe, Y., De Blic, D., Heurtin, J.-P., Lagneau, É., Lemieux, C., Linhardt, D., Moreau de Bellaing, C., Rémy, C., \& Trom, D. (2013). Sociologie pragmatique: Mode d'emploi. Politx, 3(103), 175-204.

Bazin, J. (2008). Interpréter ou décrire. Notes critiques sur la connaissance anthropologique. En Les clous dans la Joconde. L'anthropologie autrement (pp. 407433). Anacharsis.

Berger, M., \& Gayet-Viaud, C. (2011). Du politique comme chose au politique comme activité. Enqueter sur le devenir politique de l'expérience ordinaire. En M. Berger, D. Cefaï, \& C. Gayet-Viaud, Du civil au politique. Ethnographies du vivre-ensemble (pp. 924). Peter Lang.

Berrotarán, P. M. (2010). La Escuela Superior Peronista. II Congreso de Estudios sobre el Peronismo, Caseros.

Boltanski, L. (2009). De la critique. Précis de sociologie de l'émancipation. Éditions Gallimard.

Boltanski, L., \& Thévenot, L. (1991). De la justification: Les économies de la grandeur. Gallimard.

Camusso, M., \& Santiago, M. E. (2008). De la esfera militar al plano político: La Escuela Superior Peronista. Primer Congreso de Estudios sobre el Peronismo. Primer Congreso de Estudios sobre el Peronismo, Mar del Plata.

Cerutti, S. (2011). «À rebrousse-poil»: Dialogue sur la méthode. Critique, $n^{\circ} 769$ 770(6), 564-575.

Chateauraynaud, F., \& Cohen, Y. (Eds.). (2016). Histoires pragmatiques. Raisons Pratiques 25 - Éditions de l'École des Hautes Études en Sciences Sociales.

Da Silva Catela, L. (2002). El mundo de los archivos. En L. Da Silva Catela \& E. Jelin (Eds.), Los archivos de la represión: Documentos, memoria y verdad (pp. 381-403). Siglo XXI.

Ferreyra, S. (2016a). Junta Consultiva y Comisiones Investigadoras en la Provincia de Buenos Aires: Usos de la escala para pensar el conflicto peronismoantiperonismo. Revista Paginas, 8(16), 44-60. 
Pregoneros de la doctrina. Prácticas de identificación y sentidos de la acción entre los alumnos provincianos de la Escuela Superior Peronista (1952-1955)

Ferreyra, S. (2016b). Las comisiones investigadoras durante la "revolución libertadora". Usos de su archivo en la historiografía sobre peronismo y antiperonismo. Quinto Sol, 20(3), 1-25.

Ferreyra, S. (2018). El peronismo denunciado. Antiperonismo, corrupción y comisiones investigadoras durante el golpe de 1955. GEU - EUDEM.

Garzón Rogé, M. (Ed.). (2017a). Historia pragmática. Una perspectiva sobre la acción, el contexto y las fuentes. Prometeo.

Garzón Rogé, M. (2017b). Un espécimen peronista. Pruebas de identidad y modos prácticos de ser en el primer peronismo. Revista Pilquen. Sección Ciencias Sociales, 20(4), 82-95.

Grice, P. (1991). Studies in the Way of Words. Harvard University Press.

James, D. (2004). Un poema para Clarita. Niñas burguesitas y mujeres trabajadoras en la Argentina peronista. En Doña María: Historia de vida, memoria e identidad política (pp. 237-268). Ediciones Manantial.

Karush, M. B. (2016). Populism as an Identity: Four Propositions on Peronism. En J. Abromeit, G. Marotta, B. M. Chesterton, \& Y. Norman, Transformation of populism in Europe and the Americas. History and Recent Tendencies (pp. 197-212). Bloomsbury Publishing.

Knight, A. (1998). Populism and Neo-Populism in Latin America, Especially Mexico. Journal of Latin American Studies, 30(2), 223-248.

Latour, B. (2008). Reensamblar lo social: Una introducción a la teoría del actor-red. Manantial.

Lepetit, B. (1995a). Le présent de l'histoire. En B. Lepetit (Ed.), Les Formes de l'expérience: Une autre histoire sociale (pp. 349-380). Albin Michel.

Lepetit, B. (1995b). L'histoire prend-t-elle les acteurs au sérieux? Espaces Temps, 59(1), 112-122. https://doi.org/10.3406/espat.1995.3966

Leuzzi, A. (2016). Los apóstoles de Perón. La Escuela Superior Peronista (1951-1955) [Monografía final]. UTDT.

Luna, F. (1984). Perón y su tiempo. La Argentina era una fiesta (1946-1949). Editorial Sudamericana.

Mackinnon, M. (2002). Los años formativos del partido peronista (1946-1950). Siglo Veintiuno de Argentina Editores. 


\section{Mariana Garzón Rogé}

Macor, D., \& Tcach, C. (2013). El oxímoron peronista en las provincias. En D. Macor \& C. Tcach, La invención de peronismo en el interior del país. Tomo II (pp. 7-13). UNL.

Morales, V. (2017). Mundo Peronista. Una mirada "desde abajo" a la constitución de la identidad peronista durante el primer peronismo (1945-1955). Question, 1(53), 72-88.

Nachi, M. (2006). Introduction à la sociologie pragmatique. Armand Colin.

Panella, C. (2008). Mundo Peronista (1951-1955): «una tribuna de doctrina». Primer Congreso de Estudios sobre el Peronismo. Primer Congreso de Estudios sobre el PEronismo, Mar del Plata.

Panella, C., \& Korn, G. (2010). Ideas y debates culturales para la nueva Argentina: Revistas culturales y políticas del peronismo (1946-1955). EPC.

Piñeiro Iñíguez, C., \& Baschetti, R. (2015). Mundo peronista: Difusión de la doctrina justicialista en la década del '50. Jironesdemivida.

Plotkin, M. (1993). Mañana es San Perón. Propaganda, rituales políticos y educación en el régimen peronista (1946-1955). Ariel.

Plotkin, M. (2007). El día que se inventó el peronismo. La construcción del 17 de octubre. Sudamericana.

Prol, M. M. (2012). Estado, movimiento y partido peronista. La ingeniería institucional de Santa Fe, 1943-1955. Siglo XXI editores.

Quéré, L. (1994). Sociologie et sémantique: Le langage dans l'organisation social de l'experiénce. Sociétés contemporaines, 18-19, 17-41.

Qués, M. E. (2008). Estrategias persuasivas durante la campaña electoral de 1951: El caso de la revista Mundo Peronista. I Congreso de Estudios sobre el Peronismo. I Congreso de Estudios sobre el Peronismo. http://redesperonismo.org/articulo/estrategias-persuasivas-durante-la-campanaelectoral-de-1951-el-caso-de-la-revista-mundo-peronista/

Quiroga, N. (2008). Las unidades básicas durante el primer peronismo. Cuatro Notas sobre el Partido Peronista a nivel local. Nuevo Mundo Mundos Nuevos. https://doi.org/10.4000/nuevomundo.30565

Quiroga, N. (2012). De la inexistencia a la ubicuidad. El partido peronista en la historiografía académica. En O. Acha \& N. Quiroga, El hecho maldito. Conversaciones para otra historia del peronismo (pp. 83-110). Prohistoria. 
Pregoneros de la doctrina. Prácticas de identificación y sentidos de la acción entre los alumnos provincianos de la Escuela Superior Peronista (1952-1955)

Quiroga, N. (2017). La organización del territorio: Los interventores y el Consejo Superior Peronista, 1947-1955. Prohistoria, 27, 55-77.

Thévenot, L. (1990). L'action qui convient. En P. Pharo \& L. Quéré, Les formes de l'action. Sémantique et sociologie (pp. 33-70). EHESS.

Thévenot, L. (2016). La acción en plural. Una introducción a la sociología pragmática. Siglo XXI Editores.

Thomas, W. I. (2005). La definición de la situación. CIC. Cuadernos de Información y Comunicación, 10, 27-32.

Torre, A. (2011). Luoghi: La produzione di località in età moderna e contemporanea. Donzelli.

Varela, P. (2015). La teoría, el silencio y la conciencia. Conversaciones con Daniel James. Revista de la Red de Intercátedras de Historia de América Latina Contemporánea (Segunda Época), 1(2), 186-199.

Zanatta, L. (2008). El populismo, entre religión y política. Sobre las raíces históricas del antiliberalismo en América Latina. Estudios Interdisciplinarios de América Latina, 19(2), 29-44.

Recibido: $17 / 02 / 2021$

Evaluado: 22/03/2021

Versión Final: 15/04/2021 